\section{Arquitectura, Diseño y nuevos medios: una perspectiva crítica en la obra de Antoni Muntadas.} Iliana Hernández García*

\title{
Resumen / Arquitectura, Diseño y nuevos medios: una perspectiva crítica en la obra de Antoni Muntadas.
}

La habitabilidad crítica es una manera conceptual y sensorial para pensar las instalaciones del artista catalán Antoni Muntadas. En ellas se despliegan dispositivos críticos que plantean procesos experienciales y reflexivos en los cuales se escenifican las distintas formas de control y de alienación de la sociedad, especialmente desarrolladas por la publicidad, el diseño, la arquitectura, las redes, los medios de comunicación. Estas instalaciones operan como dispositivos de percepción y reflexión en el sentido en que Foucault y Deleuze los definieran, y así plantean líneas de fuga y dinámicas que permiten la ruptura.

\section{Palabras clave}

Arquitectura - Arte - crítica a los medios - Diseño - dispositivos - habitabilidad - Muntadas.

\begin{abstract}
Architecture, Design and new media: a critical perspective in Antoni Muntadas' works. Critical habitability is a conceptual and sensitive way to think the installations of the artist Antoni Muntadas. Among them, there are some critical dispositifs that propose experimental processes that shows the different ways of society control, specially developped in publicity, design, architecture, network, and media. These installations work as dispositifs of perception and reflection in the sense of Foucault and Deleuze though. In this way they offer a posibility of escape and power that allows a breaking in the control of social system.
\end{abstract}

\section{Key words}

Architecture - Art - media critics - design - dispositifs - habitabilit - Muntadas.

\section{Resumo / Arquitetura, Design e novos médios: uma perspectiva crítica na obra de Antoni Muntadas.}

A habitabilidade crítica é uma forma conceitual e sensorial para pensar as instalações do artista catalã Antoni M untadas. Nelas se despregam dispositivos críticos que expõem processos experienciais e reflexivos nos quais se desenham as diferentes formas de controle e de alienação da sociedade, especialmente desenvolvidas pela publicidade, o design, a arquitetura, as redes, a mídia. Estas instalações operam como dispositivos de percepção e reflexão no sentido em que o Foucault e Deleuze os definiram, e assim projeta linhas de fuga e dinâmicas que permitem a ruptura.

\section{Palavras clave}

Arquitetura - Arte - crítica aos médios - Design - dispositivos - habitabilidade - Muntadas.

\footnotetext{
* liana Hernández García. Ph.D. y M .A. en Arte y Ciencias del Arte con énfasis en Estética por la Universidad de Paris I - Panthéon Sorbonne. Directora del Departamento de Estética y profesora titular de la Universidad Javeriana, Bogotá.
} 
Habitabilidad ${ }^{1}$ crítica sería la forma mediante la cual explicaría las obras del artista catalán Antoni M untadas, en especial las instalativas, pues en ellas se compromete un espacio/tiempo que actúa como dispositivo, como circunstancia para la reflexión crítica de una relación maquínica de líneas de fuerza, de poder y de saber que escenarizan las formas de control ejercidas sobre la sociedad; o como construcción experiencial para la toma de conciencia y la emergencia de una o varias líneas de fuga $^{3}$ que permiten esgrimir una práctica de resistencia a través del dar cuenta de las fisuras y rupturas que deja ver cada uno de estos sistemas de representación del poder: tanto los medios de comunicación, como la arquitectura, el diseño, la publicidad.

Habitabilidad crítica hace referencia a una forma particular de estar y reflexionar en las instalaciones en video y multimediales, de imagen-espacio e imagen-tiempo ${ }^{4}$. Se refiere a un espacio/tiempo conceptual, sensible, de percepción y de reflexión a la vez, en el cual se realiza una experimentación doble, tanto a nivel conceptual como sensorial de las condiciones de control, de tres formas de dispositivo que se superponen en la sociedad actual ${ }^{6}$ : la sociedad disciplinaria: en la obra de Muntadas, a través de arquetipos como el estadio, la sala de juntas, la conferencia de prensa, el museo, la ciudad, la limosina, los centros comerciales, los bancos, aeropuertos, el jardín, la Bienal, en las cuales hay una manipulada interdependencia entre la arquitectura y el tipo de técnica de poder que se busca agenciar. La sociedad de control: la de las autopistas de información en las cuales se cree que hay una libertad pero en realidad es una forma en bucle y recurrente de establecer el dominio: Internet, la televisión, la prensa, la publicidad. Y finalmente la sociedad biopolítica o la biopolítica del poder, la sociedad de la información y luego la sociedad del conocimiento, en la cual las mentes y el conocimiento son el objeto de venta del capitalismo, y a la vez y por ello, éste - el conocimiento- ha sido sitiado, y orientado finalmente para ejercer el control directamente sobre la generación, manipulación e interrupción de la vida biológica.

Estas tres formas de dispositivos críticos y negativos ${ }^{7}$, desarrollados por Michel Foucault se evidencian en las instalaciones de M untadas. Por su parte Gilles Deleuze, presenta la idea de un dispositivo que también recrea el agenciamiento de las fuerzas como elemento fundamental, pero se centra en las líneas de ruptura, de fuga y consecuentemente de la posibilidad de escape de la maquinaria del control, por vías de la autoconciencia, de los micropoderes y a través de situarse en el lugar del afuera. Actividad procesual que igualmente puedo leer en las obras del artista Muntadas. $Y$ de manera central en estos dispositivos no podrá eludirse el tema del espacio/tiempo ${ }^{10}$ y la experiencia como fundante de la instalación misma y del propósito de cada proyecto; asimismo el tema del poder, como objetivo crítico de las instalaciones en su forma no soberana sino de control, y que en palabras de Foucault se refiere a: "lo que se ejerce sobre las cosas y las personas, la "habilidad" de modificarlas, usarlas, consumirlas, destruirlas, un poder que surge de "aptitudes" inherentes al cuerpo o transmitidas por instrumentos exteriores". Este poder se relaciona con la comunicación, "pues sin duda alguna comunicar es siempre una cierta forma de actuar sobre otra persona o personas" (Foucault, 1991:74,75).

\section{The limousine project}

Este dispositivo creado por Muntadas, consiste en un sub/espacio de la ciudad como arquetipo de poder, este lugar es el sector financiero de Manhattan, un sobre/ espacio que hace circular un vehículo de poder: la limosina, aquí pervertido y transformado su sentido, para convertirse en el lugar mismo de la evidencia de su intencionalidad. Ocurren desvelamientos a través de palabras-slogans sobre lo que este vehículo representa para la sociedad de consumo y dominio capitalista. Pero en especial llama la atención cómo se produce una inversión de roles, un contrapunto entre el paisaje de la ciudad que se ve desde el automóvil y se filma (íconos de poder puestos en los edificios de fachadas aparentemente transparentes, de bancos y multinacionales) y que el desplazamiento de la limosina permitiría visualizar a quien se desplazara al interior, pero ya no desde la admiración y supuesta confianza y seguridad de quien habitualmente mira desde el lugar de poder, sino desde la nueva mirada crítica que se instala. Así, esta visión de la ciudad, que está implícita en la mirada, pues no aparece recreada a través de la representación, dialoga con las imágenes de las diapositivas proyectadas en los vidrios oscuros del carro, las cuales efectivamente hablan del entorno que se está recorriendo, y por extensión de muchos lugares en el mundo con estas características. Se pasa de un lugar: la ciudad y sus arquetipos, a las imágenes y las palabras como el espacio del lenguaje y los símbolos, y por último al lugar de la reflexión y de una practicabilidad de la sociología crítica, por ejemplo a través de la experiencia que plantea el dispositivo: es decir, la instalación móvil. Esta emite en su conjunto una mirada, un recorrido crítico, un desplazamiento en distintos niveles: uno efectivo y real que se transforma en un desplazamiento conceptual.

\section{Stadium}

Esta obra es definida por Muntadas de manera estructural en la inter-relación entre cuatro elementos que en conjunto ejercen como intermediarios de los sistemas de representación mediática y del poder: Arquitectura, Mobiliario, Actividades, Símbolos.

Estos cuatro elementos están asignados a cada una de las esquinas de la sala oscura de la instalación y a través de proyecciones de imágenes dan cuenta de dichas características. Las actividades determinadas de antemano en estos espacios arquetípicos, actúan también como parte del sistema de control, pues conllevan en sí mismas la historia oficial de la arquitectura, en relación con las estrategias del poder político especialmente originado en Roma en esa relación entre control de masas y espectáculo que se acentúa en la era moderna con el stadium en la relación espectáculo de masas y mercado, como estrategia ahora sí definitiva y única de la política y la economía como una sola. A este respecto los observaciones del sociólogo Zygmunt Bauman sobre el panóptico ${ }^{11}$ plantean que si bien este arquetipo no es una prisión, sin embargo contiene todos los elementos de estructuración y organización del espacio a través de graderías en exhibición que miran a un solo centro 
(el espectáculo, lugar de control de la mirada) todos y cada uno de los espectadores puede ser vistos y controlados, ya que la disposición de sus sillas en círculo los deja expuestos, así mismo su mirada y conciencia están manipuladas hacia la recepción y el aplauso de un espectáculo que ofrece el mercado y que conduce al adormecimiento, al efecto sedante del ruido de la multitud, las luces, las imágenes mediáticas de los avisos publicitarios. La arquitectura pública normalmente presenta este tipo de estructuraciones, aparentemente diseñadas para el funcionamiento adecuado de sus usuarios, pero donde justamente la idea de función, es funcional para unos intereses específicos, invisibles ${ }^{12}$; es altamente rígida, poco flexible, no se escapa de la mirada, es ella misma un sistema de vigilancia, en general todos los arquetipos, como la empresa, la biblioteca, la escuela, el gimnasio, los centros comerciales, los aeropuertos, lo son.

El mobiliario denota las características de imagen corporativa, de propaganda y de idea de confort y control del orden público que el stadium en cuestión quiere procurar. Los elementos como el color y materiales del mobiliario dejan leer las características mediáticas y de mercado tanto del evento como del recinto según la ciudad o el tipo de stadium en el que se encuentre. Pero principalmente la estandarización de los elementos de las sillas y bancos juega un rol central en esa idea de ordenación, la uniformidad de color, la igualdad de las sillas, la multitud en número de ellas, define lo central del arquetipo, la imposibilidad de lo individual, el control total a que cada espectador queda expuesto al tener asignado un número dentro de ese espacio: es decir su dominación. Este tema es propio del diseño (industrial) y su relación con el mercado, que persigue invisiblemente también la homogeneización de los individuos a través de la idea de público-espectador, quien es tratado y conducido como una masa, a través de un espacio y es guiado por un sistema de señales y publicidad ya habitual, como los avisos de exit, los elementos simbólicos, de una forma similar a la conducción de un interno a ejecutar como espectáculo.

En realidad el dispositivo del stadium tiene similitudes al panóptico pero funciona horizontalmente en lugar de hacerlo en forma vertical. Es decir, si en el panóptico el lugar central estaba reservado al que vigila y domina sin ser visto o sin ser vulnerable, y las cuatro alas de su arquitectura se extienden verticalmente de este centro hacia fuera quedando expuestos a la vista de la mirada del inspector, en cambio en el stadium se produce este control a través de dos capas, la superior a la cual accede el público para ubicarse en las graderías y mirar, y la inferior a la cual accede lo mirado, el espectáculo, el agenciamiento manipulado, el interno, el héroe, el mártir, el que catalizará la acción y el deseo de la multitud.

La estructura del stadium, divide cuidadosamente a través de pasillos y escaleras de acceso, estos dos tipos bien diferenciados entre las masas que miran y las masas observadas, otorgándole el lugar privilegiado a ninguna de ellas, sino en realidad a un lugar invisible colocado en algún palco central de gradería; este es el lugar del gobernante 0 inspector principal. Aquel que mira los comportamientos de ambos niveles y toma decisiones al respecto de lo que debe pasar en esa representación del poder. Un cuarto elemento pero perfectamente inserto en el sistema, prácticamente gestor de toda la idea en nuestros stadiums contemporáneos, son los medios de comunicación como la televisión en directo y en diferido y la publicidad que multiplica esta escena hasta cada uno de los receptores en las viviendas manteniendo la posición de control y de uniformización del lugar pasivo asignado al espectador.

De esta forma se convierte a los individuos en público, se manipulan las subjetividades a favor de lo que dicta lo massmediático y se despoja de toda posibilidad de acción-reacción que no sea dentro del marco representado ya por este sistema, evidentemente hasta el punto de esquematizar los comportamientos, lo cual vemos en las imágenes sobre actividades proyectadas en una de las esquinas de la instalación.

La pieza central a la cual no se puede acceder por la cercanía entre columnas puede leerse como la forma de fuga que adquiere la obra como dispositivo, es decir la única posibilidad que tiene el visitante de generar una autoconciencia y encontrar una línea de ruptura del marco y sistema representado. Es decir que al lugar mismo del stadium no podemos (no debemos acceder) es un lugar ya sitiado (Bauman,2002) de la sociedad, es preferible ubicarnos en el afuera de una pequeña gradería exterior de dos escalones que nos permite sentarnos a observar la historia del poder a nuestras espaldas ${ }^{15}$ el espectáculo que se sucede al interior y que vemos proyectado en las diapositivas exteriores, pero somos invitados a observarlo con una conciencia crítica, a habitar críticamente ese lugar, entendiendo que la columnata y la arena del centro denotan un espacio de control, propio de las sociedades disciplinarias sobre lo cual Foucault nos explicaba que los comportamientos están en pleno bucle y relación ad infinitum dentro de un sistema de poder que se representa a través de los arquetipos.

La separación entre columnas de $40 \mathrm{~cm}$. no deja pasar el cuerpo del espectador al espacio interior de la arena, se trata de un stadium que no tiene graderías interiores, solo la representación del público a través de la videoproyección del centro. El arquetipo oficial es pervertido aquí, de suerte que las graderías se ubican al exterior, en el afuera del dispositivo ${ }^{16}$, en el margen, en el lugar donde es posible pensar críticamente lo que se sucede al interior mismo del arquetipo de control. Esta inversión de adentro/afuera es elemento central de la pieza, ya que el lugar asignado al público es cuestionado a través de su representación en espejo en las imágenes también exteriores de las cuatro esquinas; pero principalmente el lugar asignado al visitante de la instalación es obligatoriamente, quizás pese a su primera intención de querer acceder por hábito al interior del espacio arquitectónico, es definitivamente el afuera del stadium; del que ve desde afuera, del que tiene la posibilidad de crear unas líneas de subjetivación a través del espacio conceptual de percepción y reflexión que es la instalación. La arena ideológica, el espacio de lucha, el espacio de poder, finalmente queda confinado, casi encerrado entre barrotes simulando columnas griegas, prácticamente vetado a la participación, tan solo accesible a través de la mirada aún morbosa del visitante, para quien es revelado de una parte: la fuerte relación entre el stadium 
moderno, el circo romano y el anfiteatro griego, y por ende toda la carga de sentido de dominio que por una genealogía del poder en los arquetipos a lo largo de la historia, este tipo de espacios tiene; y por otra: se evidencia cómo a través de las imágenes se ha creado una mediatización de lo que es el interior de este recinto, la cual se devuelve al visitante de la instalación en términos de su propio voyeurismo, del cual al parecer no es fácil liberarse, pues los medios de proyección, de comunicación y de representación, actúan inclusive en el afuera del arquetipo mismo, y de su radio de control. Se sitúa en todos los lugares a la vez: "...se ve desde todas partes, se traslada a todos los lugares al mismo tiempo." (Bauman, 1992:40)

Sin embargo, allí reside la reflexión critica final que la pieza de M untadas pretende hacer y es cómo podremos situarnos verdaderamente en el afuera de un mundo que extrapoló las técnicas de poder, antes concentradas sólo en el espacio y sus arquetipos y ahora observemos cómo estas se multiplican abarcando también el tiempo y los contextos a través de imágenes mediáticas. Aquí el afuera, y el lugar de fuga se hace prácticamente imposible, es decir, es negativamente experimentado a través de la pieza, de forma tal que sólo la observación crítica atenta, es el último lugar de fuga posible asignado por el dispositivo al visitante ${ }^{17}$.

El sonido se une al espacio/tiempo para relacionar estas dos formas de control predeterminadas: las del espacio y del tiempo, ellas aparecen en la imagen mental a través de la memoria, son los sonidos propios de un stadium y de un televisor que transmite en directo o en diferido, el acontecimiento mediático. Es la retención habitual de la memoria en este tipo de eventos, que han dejado huella en nuestras mentes, lo cual perturba, ya que al estar dislocado de contexto (estamos en un dispositivo en una galería) evidencia la composición de estos aplausos, gritos, slogans, publicidad, y como en el efecto del ralenti en la imagen visual, aquí la imagen sonora exhibe un efecto en bucle, repetición, e insistencia, con lo cual nos hace reflexionar sobre el vaciamiento de sentido para nosotros, de estos sonidos, manifestaciones mediáticas del mercado y de agenciamientos de intereses políticos y económicos.

\section{The board room}

En esta pieza llama la atención cómo el arquetipo en principio neutral en su disposición espacial, así como en su mobiliario, se torna evidente ante la mirada en un espacio que decididamente contiene una naturaleza dominante y de control del poder, como "tercera dimensión del espacio interno" nos decía Deleuze. (1997:155) Se trata de la sala de juntas, en este caso en relación con el poder y el orden global, que desde el ejercicio de la manipulación mediática por parte de líderes religiosos, exacerba el tema del propósito de dicho tipo de espacios. Es interesante notar cómo a través de las obras de Muntadas se hace visible algo que normalmente no lo es, y es la relación estrecha entre arquetipo, tipología espacial (también contemporánea) y poder, control, dominio desde diferentes ángulos. De otra parte se hace visible la relación entre el tipo espacial y el proceso mediático que lo relaciona, de suerte que se produce una amplificación del espacio arquitectónico mismo, supe- rando las dimensiones y alcance de la sala para extrapolarse a través de los medios; es decir el mostrar cómo las acciones que se suceden en un espacio físico, en realidad superan los límites de éste y se define su impacto y afectación mucho más allá, y principalmente a través de las redes de los medios y de su maquinaria mediática. Para ilustrar esto, además la pieza produce una inversión entre lo privado de la sala y lo público de los medios, a través de las transmisiones (videos) que cada uno de los retratos exhibe en el lugar de la boca, de forma que se trae al espacio de la sala el efecto de lo masivo, pero internado en el lugar mismo de su origen. Es decir que lo massmediático vuelve al lugar de origen, la sala de juntas, origen en el sentido de ser el espacio donde se toman decisiones que afectarán a muchos. El mobiliario y decoración empleados para esta pieza, se crea especialmente a través de la disposición y características de los retratos de los líderes religiosos, también de la mesa y sillas organizadas como en una sesión directiva, acotando el rol que éstos juegan desde el lugar mismo del control.

Se produce una inversión entre lo público y lo privado, donde lo privado siendo el espacio de una sala de juntas se revela en su condición de manipular de forma interna el sistema de creencias, para volverse público a través de su exhibición en una instalación para ser visitada y generar una reflexión. De otra parte aquello considerado eminentemente público como las transmisiones de discursos a través de los medios, son extraídas de su contexto de la televisión para colocarse aquí en cada uno de sus autores, en un espacio aparentemente privado; esto en realidad demuestra cómo dichos contenidos se originan en verdaderos monopolios de la religión mediatizada, lo cual evidentemente es un espacio privado a nivel económico.

El afuera de la obra ocurre cuando presenciamos la cacofonía de los discursos, simultáneamente, en una amplitud del tiempo que por repetición nos indica que nos encontramos ante un suceso de manipulación y un sistema de control. El espacio/tiempo de la pieza se genera en la relación entre la inmovilidad de la instalación misma en cuanto a la representación del sistema de decisiones a través del mobiliario y la nomenclatura del espacio mismo contrastado con el tiempo de los videos en bucle que repiten una y otra vez los mismos contenidos y saturan el espacio de las dimensiones múltiples, principalmente temporales de lo mediático. El espacio se amplia a través de las significaciones que ocurren en los medios para desencadenar una reflexión en el afuera, en el lugar de fuga del dispositivo a través del recorrido y percepción de la pieza.

\section{The press conference}

La rueda de prensa, o conferencia de prensa, es una obra elocuente sobre la situación del control que ejercen los medios en especial la prensa y la televisión a través de sus titulares, acerca de lo que sucede políticamente a nivel global o en un país, por ejemplo como Colombia, en cuanto al tema de la situación de conflicto y opinión mediática sobre lo que acontece. Esta instalación genera un dispositivo en el cual se evidencia los medios de comunicación como un poder central, y donde en torno a una parafernalia de podium, micrófonos, el declarante 
de turno está en realidad ausente, por muchas razones; su opinión no cuenta, pues la manipulación mediática ya ha definido la noticia de antemano, pero también porque nadie es responsable, o nadie se hace responsable de lo difundido; se trata de declaraciones ya imbricadas en el sistema mismo de los medios, en su juego, que no tiene relación con una veracidad, las cuales no pueden hacer otra cosa que contribuir a la desinformación. También está ausente, porque éste ha sido desaparecido ya, o en realidad nunca ha sido reconocida su voz, o no se trata sino de una opinión que no establece nada definido, sino que puede cambiar de un momento a otro, o presentar elementos ocultos.

Sin embargo es el lugar mismo desde el cual se origina toda la transmisión, el cual se relaciona con su espejo en la transmisión misma colocada al frente en un televisor que presenta en bucle distintas declaraciones en ruedas de prensa y emisiones de noticieros, así como una alfombra de titulares de prensa que indican sobre la manera como son transformados los hechos en acontecimientos y en noticias para difundir. En medio de esta relación de fuerzas entre el origen de la palabra y su difusión transformada en los medios, se encuentra el lugar del público: vacío, inexistente, cubierto de sábanas blancas, que recuerdan su ausencia, o sus desapariciones, nunca ha estado presente en realidad, nunca ha sido convocado, simplemente actuará como receptor pasivo de la relación de fuerzas del dispositivo, o también como parte del juego de la maquinaria políticomediática. De nuevo el lugar mismo actúa estructurándose a partir del mobiliario y la forma espacial, para dar cuenta de la exacerbación de la difusión y su distribución, antes que la veracidad, o el contenido o el sentido de dicha actividad. El lugar del podium, rodeado de micrófonos, convierte el lugar de las declaraciones y las ideas en algo hiperrepresentado, lugar show, sitio altamente iluminado, sobre-expuesto, el cual no tendrá más opción que convertir allí mismo los hechos en una forma de lenguaje perfectamente mediatizada.

El espacio/tiempo de esta obra se construye a través de una contraposición con el espacio/tiempo social local y con los contenidos de las noticias ${ }^{18}$, sin excluirlo, sólo que éste opera en la relación entre el espacio de la instalación y el tiempo de la transmisión, atrayendo al lugar de origen la transmisión emitida, a un lugar en el cual el emisor ha desaparecido; la emisión en realidad ya tuvo lugar, y la ausencia está presente hace un buen tiempo. Señala esto que en realidad la difusión mediática, es una especie de sin fin, en el cual los contenidos son reciclados permanentemente, de manera que esta maquinaria se reproduce a sí misma sin necesidad de ir a las fuentes de los hechos o de su análisis en alguna otra forma de sentido. De esta manera el dispositivo se organiza a través de la inexistencia de alguien en el podium, así como de la inexistencia del público, de forma que se evidencia el sistema de noticieros como una rueda que gira por sí misma, en un espacio que se convierte en arquetipo y que agencia tal desenvolvimiento de espectacularidad para el mercado de consumo de acontecimientos.

\section{El aplauso}

Esta pieza me parece se relaciona con la anterior, en un sentido de tensión entre lo transmitido y el rol del público. Si bien en la anterior el público está ausente, y en ésta el público está decididamente presente a través del ruido cacofónico e interminable de sus aplausos, en ambas está confinado a la situación de actor pasivo, de receptor mediático e indiferente de lo transmitido, de cómplice en cierta forma de las atrocidades que se cometen, ante su ya inamovible incapacidad de manifestarse en contra, tan disminuida a causa del miedo y del escarnio que ejerce cualquiera de las formas de control del poder.

Hay una transmisión de nuevo, pero aquella ya no está en proporción a un espacio arquitectónico funcional como en la conferencia de prensa, donde en ella el televisor y su transmisión actuarían como parlante, sonido, altavoz de lo que un declarante, político, emitiría a través de los micrófonos; en lugar de ello, en esta instalación decididamente el espacio se sale de todos sus límites físicos posibles, para ser la imagen misma el lugar del espacio. Es decir, no hay espacio ya, la imagen lo ha abarcado todo (estas pantallas de gran tamaño) Se transmiten imágenes de noticieros alternando entre temas de farándula, belleza, banalidades, con temas de violencia insoportable pero real sucediéndose simultáneamente; así mismo esto se observa y transmite a diario en los noticieros. Como gran fondo, un público impasible aplaude indistintamente, uno y otro tipo de imágenes, es decir no distingue, no puede distinguir ya, la opinión pública se encuentra perfectamente manipulada desde hace 60 años en Colombia, y la instalación evidencia el hecho de que el público asigna el mismo lugar a todos los hechos como información mediática. Es interesante en esta pieza el que el espacio mismo haya desaparecido de la instalación, no hay espacio, sólo tiempo (tiempo de transmisión e imágenes) lo massmediático todo lo ha devorado, la sobredimensión de los medios en Colombia ha llegado a proporciones enormes que en esta pieza se evidencian. La noticia como ruido, los hechos ya no vistos sino escuchados, se funden en realidad con el fuerte murmullo de un solo y largo aplauso interminable, que desdibuja cualquier posibilidad de generar sentido a través de la transmisión de estas imágenes.

El afuera, y el lugar de fuga del dispositivo, se sitúa en la condición de observar con atención, en el tiempo, desde afuera del dispositivo de televisión-televidente, la suma de violencia de estas imágenes en relación directa con el aplauso. También se encuentra en el hecho de observarse aplaudiendo, en la inversión y contraposición de roles, el enfrentamiento de dos públicos, el público que aplaude, y que está reflejado en las pantallas, y el público que asiste a visualizar y reflexionar sobre la pieza; en realidad se trata o debería tratarse del mismo público (la pieza fue realizada e instalada en Colombia), y es allí donde radica su potencia, pues se sucede literalmente una autoconciencia de la situación de manipulación mediática y de pasividad de sus habitantes, es decir se revela cómo la población tiene asignado un rol de público: espectador, sin participación, sin siquiera opinión formada al respecto de los hechos. Se trata de un público que se convierte en imagen tele- 
visiva, imagen mediática, automáticamente al momento mismo de mirarse, y que se autocuestiona al sentirse mirado por este público que lo aplaude, (que aplaude las imágenes de violencia y del jet-set) pero en realidad que aplaude al espectador (visitante) mismo de la pieza, en su condición de ser inmediatamente capturado por los medios masivos.

Solo una mirada atenta, produce afecciones en los espectadores, una mirada detenida, crítica, analítica, sensible por parte del visitante, puede encontrar el lugar mismo de liberación del dispositivo, y esa misma condición es la que se indica para ejercer frente a las transmisiones televisivas que se muestran en la pieza. De esta forma se organizan líneas de fuerza entre dos públicos: uno en frenesí del aplauso, otro en actitud crítica y observación sobre el cual reside la intención de la pieza; y contamos con dos imágenes: ambas mediatizadas y manipuladas, tanto las de las transmisiones de los contenidos de los noticieros, como las del público, quien asiste inerme a su difusión. Estas dos imágenes se enfrentan con una tercera imagen mental: la del visitante, tal vez aún no mediatizada, en quien se genera una reacción, una afección, a través de una imagenmemoria de lo que ha visto a través de los noticieros, de cómo es su práctica de observación de la televisión y de cómo encuentra posiblemente una salida, una ruptura a esta condición constante en este país.

\section{Haute culture}

Alta cultura es una de las piezas más significativas de Muntadas en cuanto a la relación entre lo culto y lo popular massmediático y de consumo. Hay una imbricación entre dos tipos espaciales: el museo y el centro comercial, pero principalmente dos formas de ser de la cultura, una de élite, y otra masiva y popular. La primera de origen en la tradición europea del renacimiento, pero especialmente en su mutación moderna, formada en la historia, pero ahora manipulada y anquilosada; de otra parte una más reciente creada en la sociedad de consumo, popular, masiva, que se ubica a medio camino entre modernidad y medios, o más exactamente en una desviación que condujo desde la modernidad hacia lo massmediático y que devoró lo popular tanto como lo moderno. Pero en realidad la pieza ejerce una crítica sobre la pretendida distinción entre la alta cultura y la baja cultura, ya que en realidad el mundo actual presenta el que una no existe sin la otra, el museo está ya invadido de mucho anquilosamiento en sus formas de sentido y de presentación, lo cual ha generado inclusive una selección por parte de las masas de otros espacios más cercanos a sus deseos de consumo como los centros comerciales. A su vez, la pieza denota la confrontación entre estos dos tipos de espacio, planteada en la sociedad de hoy día, en la que el lugar del centro comercial absorbe al museo, o en la que el museo ha perdido capacidad de convocatoria y sobretodo de relevancia o de distinción frente al otro espacio. Pero finalmente la pieza de lo que habla es de una casi imposibilidad, ya bien entrado el Siglo XXI, de intentar diferenciar dos maquinarias que en últimas son lo mismo, su única diferencia es el tipo de productos que agencian, y esto por razones de la economía capitalista, del consumo, la manipulación, y la hegemonía de una cultura transformándose hacia horizontes menos elaborados en cuanto al sentido y habitando una homogeneidad interesada fundamentalmente en la lúdica, y en el vaciamiento de toda reflexión. En realidad el museo es el centro comercial y viceversa.

En la pieza, un balancín soportando en cada extremo una transmisión en directo de cada uno de los espacios mencionados, lleva el pulso de la opinión pública en cuanto al tema. $Y$ este es el elemento catalizador de la pieza, ya que se asigna el lugar de la interpretación, voir opinión fluctuante, cambiante, al público que pasa, que transita por cada uno de estos espacios y define cual de estos arquetipos es el lugar privilegiado de la cultura hoy día. La fragilidad del balancín denota la fragilidad misma de haber colocado en manos de la opinión este tipo de temas, y da cuenta de cómo la cultura se ha homogeneizado de tal forma que dicha discusión no tiene ya más sentido para el público, y cómo estos dos espacios se han vuelto totalmente intercambiables, y en ello han contribuido los medios, lo cual aparece representado en los dos monitores que proyectan el espacio pretendidamente antagónico.

\section{City-museum}

Esta instalación, ciudad-museo toma como tema el voyeurismo y el cliché con el cual varias ciudades se han convertido a través del turismo y de sus industrias culturales, en simples temas de visión fragmentada y tergiversada, despojándose de su vida doméstica, real y cotidiana. En la instalación, el espectador es invitado a observar la ciudad a través de algunos pequeños orificios, rendijas, donde ve solamente clichés de postales, imágenes recurrentes y totalmente construidas a través de los imaginarios que el comercio del turismo desea vender. El turista-espectador se ve a sí mismo en la posición de observar, fotografiar la obviedad, el montaje, la copia, la representación, el imaginario (nunca certero) de lo que una ciudad se agencia que sea. Es la mirada desatenta del consumo hacia el consumo mismo, en realidad la ciudad no está allí; se trata también de la ciudad que es literalmente despojada de su vida misma para ser reemplazada por lo que el turista desea encontrar en ella y que le ha sido informado a través de las imágenes mediáticas. Es una forma de consumo de la ciudad, opuesta a la experiencia y a una relación espaciotemporal con el espacio urbano. Es en realidad su negación. El lugar de fuga del dispositivo de control se presenta justamente cuando el espectador se observa a si mismo en la posición de turista, y genera una reflexión de toma de conciencia. La relación entre el voyeurismo como tema de varias piezas de $\mathrm{M}$ arcel Duchamp y esta obra es evidente, pues justamente da cuenta a través de la experiencia sensible de mirar, de la maquinaria que agencia a través del registro de todo el sistema del turismo y por ende de la sobredimensión de los símbolos recurrentes de una ciudad, como París - Brujas. La parafernalia que estructura todo este sistema de control tiene que ver con muchos elementos del espacio urbano que son acondicionados para el efecto: la arquitectura, las reproducciones del arte, las cámaras fotográficas y de video para el registro, el urbanismo mismo: sus paseos peatonales, los circuitos que se generan para transitar por un lado y no por otro; Barce- 
lona, Venecia, parecen estar siendo los ejemplos más literales de esta construcción mental de dichas formas de entender la ciudad, y de ser habitadas por extranjeros, siempre externos. Esta obra conectará más adelante con la pieza del Pabellón en Venecia, en la cual justamente se mostrará cómo la ciudad se encuentra despojada de si misma, deshabitada, solo existe en relación con sus eventos mediatizados y convertidos en mercancía, en el caso de Venecia: la Bienal de arte y el mapa geopolítico que construye y reconstruye permanentemente los Giardini. En Venecia se asiste a la defección política del mundo, a su absorción total por el tema de la disputa feudal del territorio, mediada por el capitalismo y el consumo mediático del arte y sus imágenes complementarias.

\section{The file room}

El concepto de archivo como intersticio entre la arqueología del saber y la genealogía del poder desarrollados por Michel Foucault ${ }^{19}$ sería la forma como analizaría esta pieza, puesto que justamente Muntadas genera un espacio abierto para otra historia, una no oficial del arte, una historia viva, que reúne las censuras del arte, ¿qué es arte? A través de ¿qué ha sido excluido de él?, no sólo desde el punto de vista de los teóricos y curadores, e instituciones, sino también desde el lugar de los presupuestos, del capitalismo, de los poderes políticos y las hegemonías históricas de ciertos países sobre otros, de ciertos nombres sobre otros, así como de temas y contenidos.

El arte, al origen lugar de apertura, de otras miradas, por definición, es evidenciado aquí como dispositivo mismo de control, de rigidez y de censura, en equivalencia con los medios mismos. El concepto de archivo es empleado en una relación crítica o de búsqueda de otros sentidos para el arte, para las redes como Internet, lugar posible para la denuncia, en lugar de recinto nuevo para las formas de consumo. Por otra parte desde el sentido del concepto de archivo, supone hacer emerger otras conexiones entre elementos históricos que den cuenta de fisuras, rupturas que la misma historia oficial ha invisibilizado. Se archiva no por acumulación, no en un sentido positivista, se archiva para dar cuenta de los olvidos, de las intenciones por ocultar, para hacer una genealogía del poder. El archivo adquiere un sentido, una vida propia, al ser alimentado permanentemente por la red, pero principalmente por la posibilidad de acceso y de vínculo entre nuevos elementos, lo que genera el sentido posible para la acumulación de una cierta información censurada.

De otra parte hacer una arqueología del arte como saber, indagando por los elementos que en su historia no se inscriben, denota el lugar único posible que el arte tendría hoy día, con algún sentido. Es decir, es en el afuera mismo del arte, en sus márgenes (como sucede con otras cosas) donde en verdad tal vez halla arte, en el sentido de una crítica, una reflexión, una evidencia sensible que genera autoconciencia, o toma de conciencia sobre algo. Con la condición de homogeneización y mercantilización de nuestra sociedad es casi imposible creer que exista arte dentro del sistema mismo de las instituciones. Si bien la obra tal vez no lo plantee así, quiero relacionarlo aquí con lo ocurrido en el nazismo, donde todas aquellas pinturas realizadas por le groupe d'artistes degénerés ${ }^{20}$, así llamados por Hitler, fueron por él excluidas, supuestamente por emplear color y no acoger los cánones marcados por su gobierno, contra el cual ellos en realidad agenciaban rupturas. Tiempo después, es en dicho trabajo artístico donde encontramos un valioso periodo.

La obra se presenta también como dispositivo espaciotemporal, al plantear un espacio mismo como lugar de archivo, un arquetipo también, casi entre archivo y biblioteca, es el lugar de la investigación de la información revelada pero también el lugar de la información oculta. Es la biblioteca de la Edad Media, explorada y surtida con las más desconocidas informaciones, es el archivo y la arqueología misma del arte en el sentido de Foucault, es cómo trazar nuevamente la historia del arte pero desde las censuras que éste ha tenido. $Y$ de otra parte se trata de la contemporánea yuxtaposición de información en cascada propia de un nuevo medio masivo: Internet, en el cual conviven elementos tanto veraces como inverosímiles y fuente de todas dudas, pero también buena fuente del afuera de otros hechos vetados, velados por los mecanismos invisibles del consumo del arte y su maquinación económica. Me parece que el contenido de este archivo se mueve entre la investigación sobre dichas censuras, y su otra historia, en contrastación con la reconocida, y entre la anarquía de lo manifestado a través de un medio como Internet.

En la mitad de ello está el público y el rol que éste adquiere para observar, discernir, suponer, entender, escoger sobre lo que allí está expuesto. Al final no existe duda alguna, y sobre cada historia recae una porción de veracidad, estableciendo en todo caso una continuidad sólida de lo que ha sido la censura. El espacio físico actúa en mucho como gran metáfora de almacenamiento de datos y su posibilidad de manipulación, su oscuridad, estructuración a través de simbólicas gavetas, la confrontación entre el espacio físico de un archivo y el espacio virtual de Internet, la inmovilidad del primero, la maleabilidad pero también actualización y amplia distribución y acceso del segundo.

El archivo físico denota un espacio físico, controlado, con dueño, casi autor, moderno, el espacio virtual casi su contrario, hipermoderno. En cierta forma asistimos a la coexistencia de dos tipos de dispositivos de Foucault, explicados al inicio de este documento: el primero del archivo físico: de sociedades disciplinarias como la biblioteca, y el segundo: de las sociedades de control: las autopistas de información, aparentemente libertarias, pero en realidad inmersas en otras formas más extendidas de dominio.

\section{Between the frames: the forum}

Esta obra antecesora y relacionada con el Pabellón de la Bienal de Venecia, organiza un dispositivo en el cual la imagen-espacio y la imagen-tiempo se imbrican para dar lugar a una relación de distribución de la paradójica forma de operación de un saber como el arte, conformado por instituciones, docentes, curadores, mercaderes, donde el espectador flota entre distintas formas discursivas que dislocadas de su contexto a través de imágenes alusivas a formas mecánicas de la ciudad, revelan los mecanismos invisibles de la genealogía del 
poder oculto bajo todos estos procedimientos del arte y sus circuitos. La imagen-espacio está puesta a través del dispositivo general que reparte en porciones aparentemente iguales y de forma circular, un lugar de salas y presentaciones de los distintos capítulos que lo conforman; a su vez se reparten las imágenes de video difundidas en cada televisor, las cuales se ubican en las salas donde se ilustra con espacios arquetípicos que recuerdan formas mecánicas del mercado y la era industrial y urbanizada; de otro modo la imagen-tiempo es representada espacialmente por los discursos que estas grabaciones de profesores, teóricos, y demás agentes de la maquinaria van argumentando en otra forma de archivo, distinta a la anterior, pero en la cual de forma opuesta se agencia lo reconocido, no lo censurado, los instrumentos mismos principalmente del lenguaje y de la voz en relación con un poder centrado en nomenclaturas que unos y otros reciben en la repartición de un sistema de control.

La ruptura del dispositivo se sucede tanto en la relación entre los discursos y las imágenes-espacio del contexto urbano (casi mecánicas) que las alternan; esta dislocación genera la evidencia sobre la manipulación que se ejerce y la relación con el entorno, y por otra parte en la disposición espacial misma del lugar de la instalación, su forma circular como una repartición, y su fragmentación en capítulos, secciones, cuadrantes, da cuenta en síntesis de otra arqueología del arte como saber; y de su sobrestructuración, pero especialmente acerca del por qué se presenta la organización del arte de esta forma, pues una serie de elementos externos, del contexto y de la sociedad mediática y de consumo en la que nos encontramos determinan también y de forma fuerte lo que en este sistema está sucediendo.

\section{CEE Project}

Un proyecto que destaca el uso de un elemento básico de decoración y mobiliario: un tapete o alfombra, un objeto habitualmente estandarizado y reproducido a través de la maquinaria industrial, sin otro fin distinto al comercio, la publicidad de imágenes corporativas, y el uso cotidiano e indiferente; en esta pieza es reemplazado por el mismo elemento pero pensado por el artista para ejercer un lugar de equivalencia de estas mismas características aquí descritas, a algo discursivamente agenciado por los gobiernos y los sectores de poder económico como importante y de alta participación y compromiso de sus ciudadanos: "la conformación de la comunidad económica europea". Llama especial atención que la crítica se ejerce desde conseguir el lugar de equivalencia entre el diseño industrial y los agenciamientos de poder y consumo de por ejemplo el proyecto de Europa. Los intereses del diseño industrial se evidencian perfectamente ligados a los de la identidad corporativa y sus objetivos de manipulación, a la publicidad de otra forma de productos de consumo, en este caso una forma de relación económica, sobre la cual en su momento los habitantes y ciudadanos de cada país no estaban de acuerdo ni habían propuesto. Un dispositivo que revela los enunciados discursivos de un proyecto global en proceso, centrado en el intercambio económico no equitativo y la ausencia de referencias en lo social y cultural.

\section{On translation: I giardini}

On translation designa un proceso abierto aún, desde el cual se realizan aproximaciones diferentes a temas distintos. On translation: I giardini, una instalación multimedial reciente, preparada para la Bienal de Venecia como el Pabellón español. En ésta se organiza un dispositivo complejo compuesto, conformado por varias otras piezas, que son colocadas en diálogo con este contexto. El primer tema a resaltar es el de la disposición espacial del pabellón, un centro y una periferia, como repitiendo la organización político-económica de los países que asisten y participan del dominio de esta maquinaria de mercado que es la Bienal.

Quiero empezar por uno de sus vértices, y no por el centro, resaltando dos de sus elementos: los videos On listening y $O n$ view. Estos dos videos se ubican al interior del pabellón pero en sus márgenes, pues el Pabellón realiza una geopolítica a su interior, es decir ubica en el lugar central un espacio del vaciamiento y del descanso y del pasar a través, donde aparentemente no sucede nada, pero en realidad es el lugar mismo de la ironía pues éste representa el centro de la hegemonía de los países invitados con pabellón en la Bienal. Sobre este tema volveremos más adelante, para analizar los aspectos de mercado del arte y del mercado inmobiliario, la especulación urbana, y el funcionamiento político global, representado a escala dentro de la Bienal, que opera como un ambiente provisto para la macroeconomía mundial. Volviendo a la ubicación de los videos mencionados y a la pieza A plauso, y The bank, estos se encuentran en el afuera del espacio/tiempo de la propia Bienal, haciendo funcionar el pabellón como un lugar posible para decir lo que ha quedado siempre excluido, por el dominante mapa geopolítico. On listening, presenta una lectura del espacio-tiempo en una sociedad también dominante, pero mostrando un contexto cotidiano, perfectamente mediatizado por el teléfono celular, mostrando un paisaje arquitectónico y a la vez tecnológico y mediático sobre el escuchar, pero donde en realidad no se escucha nada, sus protagonistas hablan por teléfono celular en un espacio de corredor relativamente pequeño, y sin hablar entre ellos, sin siquiera verse; este plano único muestra una forma del vaciamiento de sentido, la dislocación de las funciones del espacio y la perspectiva sumamente abierta del horizonte de un espacio físico, que pierde su sentido como tal y se proyecta a otros lugares a través de la escucha que sus protagonistas suponemos realizan. El video es también una forma de definir la condición actual de incomunicación en el espacio y exclusiva comunicación en la distancia en el tiempo. Privilegio del tiempo sobre el espacio, desproveerse del espacio y sus lugares y contextos para asignarle una función siempre de paso, accidental, y atender los requerimientos del consumo de la telecomunicación. Por otra parte el video por extensión metafórica denota lo que sucede en la Bienal misma, cientos de personas que hacen filas, desconocidas, ausentes de todo diálogo in situ, que asisten a un espectáculo mediático que siempre hace referencia a otra cosa, nunca a sí misma, ni a la ciudad de Venecia, sino extrapolándose a otros significados externos y conexiones hasta perder el límite y el fin de dicha cadena. On view, hace relación al espacio/tiempo pero del mirar, 
mientras el anterior estaba planteado sobre el escuchar, estas dos actividades básicas son principales en la sociedad de imágenes audiovisuales contemporáneas mediatizadas. También en este mirar, no vemos nada, no sabemos qué ven los protagonistas de esta imagen en movimiento. Ambos videos son auténticas imágenestiempo en el sentido que Deleuze (1986) explicaba: pues presentan la ruptura misma de su continuidad, a través de la tensión que ofrece el bucle, la repetición, la insistencia, la imposibilidad de ver lo mirado, la ausencia de sentido, y sin embargo la cotidianidad de este tipo de imágenes, y cómo las reconocemos en tanto que universales. La ruptura o fisura de la imagen-tiempo se presenta por fuera en realidad del espacio y de las estructuras narrativas de la imagen audiovisual, se trata de una imagen-tiempo que emerge como forma de una genealogía del poder que se le hace a las actividades cotidianas, y en especial aquí a la Bienal como sistema. La imagen-tiempo supera los límites del espacio y sus referencias de contexto, que incluían también la función, la forma y el contenido, para desplazarse hacia un dispositivo crítico, el cual opera no por el espacio mismo determinado, sino por la transformación que emerge en paralelo con la imagen-tiempo, en el horizonte mismo de mostrar las fisuras como un acontecimiento. Los enunciados de dichos lugares se organizaron en la modernidad a través de imágenes-espacio, en términos de Foucault: de dispositivos disciplinarios, arquetípicos; las rupturas de los dispositivos instalativos críticos como los de Muntadas se organizan a través de imágenestiempo que equivaldrían a los dispositivos de control, donde el control no se ejerce desde el dominio del espacio mismo sino desde elementos que se encuentran ubicados fuera, en este caso las telecomunicaciones, tanto en el escuchar como en el mirar, y en sus relaciones con el consumo y el tipo de sociedad de mercado de que disponemos. En este sentido es más complejo pensar en un dispositivo crítico que dé cuenta de rupturas en cuanto al segundo tipo de dispositivos, pues en ellos ubicar el afuera del poder, debe superar inclusive los límites del afuera mismo del espacio, para hacer emerger una imagen-pensamiento a partir de una imagen-tiempo. Esto, a mi manera de ver, es lo que consiguen los videos de On listening y On view.

Volviendo al plano general de On translation: I giardini, vemos el centro mismo del pabellón como una crítica a la traducción, pero a través de la estrategia misma de la traducción, como una forma de ofrecer un caleidoscopio, de pervertir el sentido mismo de la traducción, para instalar un dispositivo que revele los resquebrajamientos, las fisuras reales que ya acumula hace muchos años el sistema de la Bienal. En cierta forma es análoga con el hecho mismo de las instalaciones multimediales, al trabajar con nuevos medios pero al mismo tiempo hacer de ellos el objeto de su crítica y análisis. Se trata de ampliar el sentido de los medios, denunciando, evidenciando, e inclusive construyendo otros sentidos posibles hasta ahora no descubiertos. Digo que el pabellón de por sí es una traducción ${ }^{21}$, porque traduce lo que la Bienal es, a través de una compleja instalación conformada por varias piezas, que aprovechan algunas de ellas, su ya conocimiento por parte del público; es decir el pabellón traduce las relaciones geopolíticas, el mercado del arte, como maquinaria moderna en la Bienal, el lugar de consumo, que como espacio físico no tiene otra cualidad, que la de ser un lugar de paso, "un descanso", en principio ¿inocente?, desprevenido, anodino como son prácticamente todos los nuevos lugares de paso del mundo y de este tipo de parques temáticos y vida social actual ${ }^{22}$; luego poco a poco se va desvelando el otro nivel, el nivel de las rupturas, en el cual encontramos una genealogía del poder de la Bienal, a través del kiosco de información que permite ir analizando las relaciones históricas entre por ejemplo las políticas más doctrinarias y dictatoriales de países como Alemania o Italia y la tipología arquitectónica empleada en dichas épocas, o el auge que ello tuvo en la Bienal, mostrando que en mucho la historia del arte y la arquitectura coinciden plano por plano con la historia de la política y la economía mundiales.

Esto es en realidad lo que sucede en el centro del Pabellón, cuando el visitante cansado de las largas filas y espera para acudir a cada pabellón, entra a éste y encuentra el tema del vaciamiento, propiamente intencionado que plantea el artista y dependiendo de la posibilidad del espectador de ubicarse en el afuera del tema, se orienta por indagar sobre los elementos que presenta este lugar de información, tan habitual en los aeropuertos, como cualquier otro elemento de mobiliario del sistema de control espacial de uno de estos espacios de eyección como los llamara Paul Virilio, para darse cuenta que la función y el rol del kiosco ha sido dislocada a través del sentido, para dar lugar a uno de los primeros elementos de ruptura de la instalación como dispositivo crítico.

Avanzando en el pabellón obtenemos listados, de por ejemplo los países invitados a la Bienal, y en su reverso de los países nunca invitados que no cuentan con un pabellón aquí, y esto organizado dentro de un elemento de mobiliario público generalmente utilizado para señalética de un aeropuerto, a lo que nos hemos acostumbrado como que jamás contienen elementos contradictorios, o paradójicos o inductores de cambios de sentido; caso exactamente contrario en las intenciones del artista, quien justamente designa para este elemento: el afichador, el rol de subvertir el sentido mismo del elemento sin cambiar sus modificaciones de forma y materiales. Esta estrategia fue explicada de forma interesante por Deleuze, quien argumentaba que lo que habría que hacer no son transformaciones en choque, sino miradas caleidoscópicas que desde dentro crearan fisuras a los sistemas, parafraseándole: pervertir el sistema desde dentro para operar a través de microrupturas desde lo molecular para subvertir el orden de lo molar.

Las imágenes fotográficas de filas de gente que espera para poder acceder a cada pabellón recuerdan de nuevo los parques temáticos, instrumento último del urbanismo en asocio con la economía capitalista, forma de marketing y especulación inmobiliaria basada en el control del ocio y su generación de valor económico a través de la conducción de acciones sobre acciones que ocupan el tiempo libre y a los ojos del mercado "desprovisto de acción" pues estaba "desprovisto de beneficios económicos" ; éste ahora es manipulado a través de largas, extensas y anodinas esperas para acceder a ver el vaciamiento mismo; se asiste a mirarse asistiendo en el 
espacio/tiempo de la espera, para ver en realidad hacia dentro de sí, en la superficie de la piel de lo urbano, que coincide plano por plano con la de la economía. En ello Foucault anunciaba ya la llegada del control del tiempo de ocio, a través de operaciones estratégicas y nuevos aparatos de control y gobierno que ordenarían para sus beneficios, lo siempre permanente y reacio a ser organizado, es decir el tiempo y el comportamiento individual $^{23}$.

Como conclusión a este documento pensaría en la fabulosa relación casi plano por plano con la forma de entender el dispositivo entre Foucault-Deleuze desde el pensamiento y M untadas en la creación de sus obras; me llama especialmente la atención cómo el dispositivo es a la vez la descripción maquínica misma de las formas de control y dominación de distintas épocas, modos, sistemas, ejercicios del poder y del gobernante o de las instituciones, y cómo se desencadena este concepto mismo incluyendo su ruptura; en las obras instalativas de Muntadas es especialmente claro puesto que pudimos en este texto descifrar cuál era el lugar de fuga, el agenciamiento de la línea de subjetivación, el lugar posible para la toma de conciencia, para el ejercicio de esa habitabilidad crítica que permite entender el dispositivo de control y al mismo tiempo el dispositivo crítico en el afuera que se encuentra en el adentro del dispositivo mismo, cuando éste se crea como instalación. Esta duplicidad de cada obra y de contención del tema en sus dos versiones es muy interesante porque en realidad el pensamiento procede de esa forma, así la experiencia de estos temas procede también de singular manera.

\section{Notas}

${ }^{1}$ He tratado este tema en Hernández lliana, Estética de la habitabilidad y nuevas tecnologías (Bogotá: Centro Editorial Javeriano/ Departamento de Estética, 2003) y Mundos virtuales habitados: espacios electrónicos interactivos (Bogotá: Centro Editorial Javeriano/ Departamento de Estética, 2003)

${ }^{2}$ Concepto de dispositivo en Michel Foucault, el cual tiene que ver con que el dispositivo nutre una crítica negativa que permite estar siempre alerta, tomar conciencia, y comprender lo que acontece de forma reflexiva.

${ }^{3}$ Concepto de dispositivo en Gilles Deleuze, que se inscribe en una lógica vitalista; en él habría siempre un intersticio, una fisura, un lugar de fuga, que permitiría la emergencia de lo nuevo, como ruptura con la historia y la dominación.

${ }^{4}$ "El modo de ser del pensamiento se constituye a partir de una imagen-espacio y una imagen-tiempo y estas imágenes establecen el fundamento estético del pensar." (Garavito, 1991:6)

${ }^{5}$ Ver el desarrollo de esta concepción del espacio tanto de percepción como de reflexión, lo cual define las instalaciones, en mi libro: Mundos virtuales habitados: espacios electrónicos interactivos (Hernández, 2003).

${ }^{6} \mathrm{Si}$ bien, desde los textos de Foucault cada una de ellas se conceptuó como apareciendo una tras otra en momentos distintos de la historia, es evidente comprender que ninguna de ellas va desapareciendo o es reemplazada, sino que en realidad todas ellas se reúnen y sobreponen en el momento actual. Sin embargo es interesante presentarlas aquí en el orden en que emergieron y se han ido acumulando como formas de control, y se pueden leer aconteciendo entre el Siglo XVIII, el XIX y el XX.
"Tomamos aquí la palabra "negativos" como negatividad, concepto desarrollado por el esteta Théodor Adorno, quien describe una forma particular del pensamiento para establecer una crítica que no pretende sintetizarse o mutar luego hacia solución alguna o afirmación o positividad, sino que se mantiene en su condición crítica y en ello radica su potencia. ${ }^{8}$ Es necesario entender que aquí el concepto de ruptura coincide plano por plano con el de emergencia, o el de nuevo, no el sentido de novedad o de evolución, ni mucho menos de progreso o moda, sino justamente en el sentido de inactualidad, para una posibilidad de surgimiento de la diferencia, como práctica de resistencia, objeto mismo de las instalaciones.

${ }^{9}$ El lugar del afuera para Gilles Deleuze, (aunque también fue desarrollado por Michel Foucault) tiene que ver con que el pensamiento, y por ende la imagen-pensamiento sólo se sucede en las márgenes del saber, del orden, y de la historia. Como ejemplo al tema también nos dice Foucault: "Lo nuevo no procede de una sociedad de discurso, ni de un centro académico, sino del afuera de los ordenamientos vigentes en el saber de una época." (Foucault, 1991:42)

10 "El espacio y el tiempo pueden comprenderse como la fuerza o potencia de aglutinación del discurso. Más que ser la forma del decir o del pensar, la imagen-pensamiento es la fuerza de un espacio y de un tiempo que relacionan automáticamente una idea y otra idea, un pensamiento y un objeto, un autor $y$ un lector, etc." (Garavito, 1991:21).

${ }^{11}$ "El panóptico puede describirse como un modelo de la sociedad total; un modelo en miniatura confinado a un edificio rotatorio, un modelo idealizado de una sociedad perfecta." (Bauman, 1992:37). Por su parte, Michel Foucault le llamó: "dispositivo prisión" o "máquina óptica para ver sin ser visto, inmersa en una historicidad de los dispositivos, que coincide con los regímenes de luz". (Deleuze, 1997:156).

12 "En el Panóptico la libertad de algunos hace que la dependencia de otros sea no sólo necesaria sino rentable; la falta de libertad de una parte hace posible la libertad de otra" (Deleuze, 1997:34).

${ }^{13}$ "Los internos del panóptico (esta máquina de control universal) están definidos únicamente por la intención a la que su confinamiento ha de servir -la intención desde luego de quienes los internan. Las condiciones bajo las cuales se los coloca mientras están confinados deben ser calculadas cuidadosamente para servir de la mejor manera a los fines de quienes los confinaron". (Deleuze, 1997:22,23).

${ }^{14}$ En Vigilar y castigar (1990), Michel Foucault investiga y da cuenta de cómo la ejecución de un sentenciado por parte del gobernante, dispuesta como acto público y de espectáculo, fue prohibida y desapareció hasta hace muy poco tiempo, ya entrado el Siglo XX, si bien evidentemente se reproduce ahora de otras formas.

${ }^{15}$ Se pregunta el filósofo Edgar Garavito cuál es el lugar de la historia para Foucault: es lo que queda a sus espaldas, es de lo que nos diferenciamos. Entonces ¿qué tiene Foucault al frente? Lo in-actual del acontecimiento, aquello que podemos llamar el evento, o fuerza del acontecimiento que impide integrarlo a un molde temporal. (Garavito,1991a:36)

${ }^{16}$ "Un dispositivo es una especie de ovillo o madeja, un conjunto multilineal. Está compuesto de líneas de diferente naturaleza y esas líneas no abarcan ni rodean sistemas cada uno de los cuales sería homogéneo por su cuenta (el objeto, el sujeto, el lenguaje) sino que siguen direcciones diferentes, forman procesos siempre en desequilibrio (...) Los objetos 
visibles, las enunciaciones formulables, las fuerzas en ejercicio, los sujetos en posición son como vectores o tensores. Las dimensiones de un dispositivo están dadas en términos del decir y del mirar: son curvas de visibilidad y curvas de enunciación. Son máquinas para hacer ver y para hacer hablar." (Deleuze, 1997:155)

${ }^{17}$ Dice Deleuze: “En un dispositivo hay líneas de fisura, de fractura. Desenmarañar las líneas de un dispositivo es en cada caso levantar un mapa, cartografiar, recorrer tierras desconocidas. A esta fisura o ruptura le equivale el trazo de una línea de subjetivación, que debe hacerse en la medida que el dispositivo lo deje o lo haga posible. Es una línea de fuga, se escapa a las líneas de control." (Deleuze, 1997:156)

${ }^{18}$ Para distinguir estos dos tipos de espacio y tiempo entre los de la historia y los del dispositivo como instalación veamos lo que nos dice Edgar Garavito a propósito del pensamiento de Michel Foucault: “El espacio y el tiempo social son exteriores al espacio y el tiempo del pensamiento. Pero el espacio y el tiempo del pensamiento tampoco debe ser confundido con un espacio y un tiempo referenciales, es decir, con el espacio y el tiempo de los que habla el pensamiento elaborado discursivamente. Cuando se dice que hay un espacio y un tiempo del pensamiento no debe creerse entonces que se trata de las condiciones sociales e históricas en las que se desenvuelve el pensamiento, ni tampoco del espacio o del tiempo de los que el pensamiento habla. El espacio y el tiempo del pensamiento son una estética inmanente al propio pensamiento y no se hallan fuera de él." (Garavito, 1991a:20)

19 "La Arqueología del saber es la descripción de las cosas dichas en relación con el sistema de formación de los enunciados, remite a una imagen-espacio, mientras que la genealogía del poder en tanto que emergencia de una práctica remite a una imagen-tiempo." (Garavito,1991a:25,26).

${ }^{20}$ Ver investigación de Olivier Revault d' Allones acerca de l'art dégeneré, desde la estética negativa de Théodor Adorno.

${ }^{21}$ Al respecto de Foucault, Garavito explica: “El objetivo quizá no sea el de descubrir qué somos, sino el rechazar lo que somos. Tenemos que imaginar y crear lo que podríamos ser para librarnos de esta especie de "doble atadura" política que consiste en la simultánea individualización y totalización de las estructuras modernas del poder." (Garavito, 1991a:69)

${ }^{22}$ El artista acude al hecho de que el ejercicio del poder se realiza no a través de enunciados jerárquicos o con autores y responsables como uno supondría, y perfectamente diferenciados e identificables que permitiría ejercer hacia ellos un distanciamiento, sino todo lo contrario, éste se ejerce desde un mimetismo hoy por hoy muy alto entre todos los elementos, incluyendo los más banales y sencillos de la vida social, pública o privada como por ejemplo el mobiliario, la arquitectura; en relación a ello, Foucault explica: "Las relaciones de poder están profundamente arraigadas en el nexo social, no reconstruidas "sobre" la sociedad, como una estructura suplementaria cuya eliminación radical uno pudiese quizás soñar." (... )" De forma que el análisis, la elaboración, el cuestionamiento de las relaciones de poder (...) es una tarea política permanente, inherente a toda existencia social (... )." (Garavito, 1991a:32)

${ }^{23}$ "El ejercicio del poder consiste en guiar la posibilidad de conducta y colocar en orden la posible consecuencia. Es directamente un control sobre la acción, o un control desde la acción sobre otras acciones. Supone necesariamente sujetos libres, en desarrollo de una acción, cuyos comportamientos puedan ser conducidos." (Garavito, 1991a:35)

\section{Bibliografía}

- Bauman, Zygmunt. (2002). Sociedad sitiada. Madrid: Alianza. (1992). Libertad. Madrid: Alianza.

- Deleuze, Gilles. (1997). ¿Qué es un dispositivo? En A.A.V.V Michel Foucault, filósofo. Barcelona:Gedisa.

(1993). Différence et répétition. Paris: Presses Universitaires de France.

(1992). Le bergsonisme. Paris: Presses Universitaires de France.

(1992). La imagen-movimiento: estudios sobre cine. Barcelona-Buenos Aires-M éjico: Paidós.

(1990). Pourparlers: 1972-1990. Paris: Minuit.

(1988). Le pli: Leibnitz et le baroque. Paris: M inuit.

(1986). La imagen-tiempo: estudios sobre cine 2.

Barcelona-Buenos Aires-M éjico: Paidós.

(1986). Proust et les signes. Paris: Presses Universitaires de France.

- Duguet, Anne-M arie. (1994). A propos de quelques implications artistiques de lînteractivité. En Mutations de lîmage: art cinéma/video/ordinateur. Compilación de Maria Klonaris y Katerina Thomadaki. Paris: A.S.T.A.R.T.I. (1994). Video, la mémoire au poing. Paris: Hachette Littérature.

(1988). Dispositivos. En Video-comunicaciones, n.48. Paris: Seuil.

(1988). Le double hérétique en Paysages virtuel, Cauquelin Anne y Duguet, Anne-M arie (compiladoras). Paris, Dis/Voir.

(1986). Voir avec tout le corps. En Revue d Esthétique n. 10. Paris.

- Duguet, Anne-Marie, Peyron Jean-M arc. (1991). L'Odysée

du virtual. Paris: La Documentation Francaise.

- Foucault, M ichel. (2004). Nacimiento de la biopolítica. París: Gallimard.

(2001). Defender la sociedad. M éjico: Fondo de Cultura Económica.

(2001). Nacimiento de la clínica. Méjico: Siglo XXI. (1991). El sujeto y el poder. En comp. Edgar Garavito. Bogotá: Carpe Diem.

(1991). Las palabras y las cosas. Méjico: Siglo XXI. (1990). Vigilar y castigar. Méjico: Siglo XXI.

(1978). Arqueología del saber. M éjico: Siglo XXI.

- Garavito, Edgar. (1991a). El sujeto y el poder. Bogotá: Carpe Diem.

(1991b). Tiempo y espacio en el discurso de Michel Foucault. Bogotá: Carpe Diem.

- Heidegger, Martin. (1958). Habiter, penser, batir y La question de la technique. En Essais et conférences. Paris: Gallimard. - Hernández, lliana. (2005). Estética, ciencia y tecnología: creaciones electrónicas y numéricas (compiladora y coautora), Departamento de Estética. Bogotá: Centro Editorial Javeriano. (2003). Mundos virtuales habitados: espacios electrónicosinteractivos, Departamento de Estética Bogotá: Centro Editorial Javeriano.

(2003). Estética de la habitabilidad y nuevas tecnologías (compiladora y coautora) Departamento de Estética. Bogotá: Centro Editorial Javeriano.

(2002). Arte, arquitectura y nuevas tecnologías de información y comunicación. En Revista Aisthesis, Instituto de Investigaciones Estéticas. Facultad de Filosofía. Chile: Ed. Universidad Católica de Chile. (2001). Espacios inmersivos. El retorno del cuerpo. En Cuerpo e imaginarios. Michela Pentimalli (organiza- 
dora). Facultad de Arte, Facultad de Filosofía. La Paz : Universidad Mayor de San Andrés. Galería Simón I. Patiño.

(2000). Estética contemporánea: producción de subjetividades en el cruce entre arte, ciencia y nuevas tecnologías. Bogotá : Centro Editorial Javeriano. (2000). Inteligencia computacional en el arte y la arquitectura. Medellín: Ed. Universidad Nacional de Medellín.

(1997). Habitabilité des images en mouvement. Vers une architecture transformable. Tesis de doctorado en arte y ciencias del arte, énfasis en estética, con la dirección de Anne-M arie Duguet. Universidad de ParisI Pantheon Sorbonne, Paris: Septentrion.
- Muntadas, Antoni. (2005). Catálogo, Muntadas: On Translation: I Giardini, Pabellón de España, 51ª̈ienal de Venecia.

- Virilio, Paul. (1991). La inercia polar. Madrid: Trama.

(1989). La máquina de visión, Madrid: Cátedra.

(1988). Estética de la desaparición. Barcelona: Anagrama.

(1984). L'espace critique. París: Bourgois.

(1984). Logistique de la perception: Guerre et Cinema I. París: Editions de l'Etoile.

(1981). La troisieme fénetre. En Cahiers du cinéma, n. 322. París

(1980). Un urbanisme teleobjectif. En Videoglyphes, n. 3-4. París. Catálogo: Video, paysages, architecture. (1977). Vitesse et politique. París: Galilée. 